\title{
1. Becoming a business-to-business marketing scholar
}

\author{
Adam Lindgreen and C. Anthony Di \\ Benedetto \\ In collaboration with Ko de Ruyter, Lisa \\ Ellram, Christian Grönroos, Michael Hutt, \\ Douglas M. Lambert, Ajay Kohli, Selma \\ Kadić Maglajlić, Matthew Robson, and Michel \\ van der Borgh
}

\section{INTRODUCTION}

In our graduate studies, we learn to stand on the shoulders of those who have gone before. We seek to make research contributions that advance our theoretical and conceptual understanding of what we are studying. We may not, however, get a chance to learn from the collective learning of our senior colleagues regarding success in our chosen career. This is a twofold issue. First, an early-stage academic needs guidance on how best to use time and resources to prepare for a successful career: what he or she should do, and what should be avoided. Second, what are the specific challenges faced by business-to-business (B2B) marketing researchers, that is, the readership of Industrial Marketing Management? What practical advice would the most successful B2B academics provide so that their younger colleagues can get their careers off to a good start? While all of us benefit from the insights of our dissertation chairperson and committee and other thought leaders we may encounter along the way, what if we brought together top B2B academics into a kind of virtual forum? Our objective here is to gather and assemble thoughtful career advice from some of the most published authors in B2B marketing to gain a sense of "how they did it."

To accomplish this objective, we decided to approach some of the most preeminent academic thought leaders in B2B marketing and ask them to reflect on their careers and to provide advice for doctoral students and early-career 
academics. Each contributor agreed to submit responses via e-mail to four questions in open-ended fashion: what worked for them in their careers, what did not work, what were the dilemmas they encountered, and what overall advice would they give to junior researchers starting their academic career. In the following sections, we have distilled these reflections down into a collective wisdom, organized around the four interview questions. We conclude with a few observations of our own.

\section{WHAT WORKS}

Our contributors had much advice for young scholars regarding what to do to advance their careers. We have organized their advice on what works into the following five sub-categories, each of which we discuss next:

- Collaborate with academics.

- Collaborate with practitioners.

- Travel off the beaten path.

- Stay focused.

- Have fun and celebrate successes.

\subsection{Collaborate with Great Academics}

The old saying is that "no man is an island," and that certainly is true for academics. Throughout one's career, there are many opportunities to work with academics who share research interests or have first-hand knowledge about the academic process. Some of these academics we inevitably meet - thesis supervisors, lecturers, and fellow students - early in our careers; others - peers and our own students - at later stages. Further, if we take the initiative to provide service to our colleges and to professional associations, we can increase our contacts exponentially. Ajay Kohli notes:

I ... had the opportunity to work with very smart and interesting people in my doctoral program and, following that, in my professorial career. I learned an enormous amount about doing research and effective writing from them. It was a blast to work with them and, unsurprisingly, I did my best work with them ... [In addition,] I was very fortunate to have the opportunity to serve in various service roles such as the Associate Dean responsible for launching a new Ph.D. program at Emory University, Editor-in-Chief of the Journal of Marketing, AMA Academic Council member, and EMAC VP of Global Relations. These roles brought me in contact with a large number of junior and established colleagues, broadened my intellectual horizons, and provided opportunities for contributing back to the community. (Kohli) 
Importantly, we are part of an academic community. Working with a team of collaborators toward a common goal pushes our research agendas forward, and also helps keep us grounded and focused. Ko de Ruyter writes about the value of a collaborative team that includes practitioners, as well as academics:

My mantra throughout my career has always been to work with a set of collaborators who like to work hard and play hard. I find it very rewarding to work late in the office with a group of people trying to meet a deadline, order pizza in, watch football, and go out for a drink to celebrate whatever milestone (like making the deadline by one minute). I know that some people keep insisting on solo-authored papers, but where is the fun in that? Beyond this, it seems virtually impossible for one person to possess the very wide range of capabilities needed to publish in academic journals these days. This is especially true for B2B research where relationship management goes hand in hand with the latest analysis skills. Also, it is ultimately about the quality (i.e., rigor and relevance) of the research and the way in which it pushes the boundaries of the knowledge base, rather than the composition of a research team or the vita of an individual researcher. Over the years, I have led research teams that tackle specific issues of a grand B2B theme (e.g., technology in industrial marketing). We run these groups, which consist of all academic ranks, in cooperation with companies, trying to solve real-life challenges. Engaging with businesses over longer periods of time in industrial markets is essential for getting access to and being able to collect data. But most of all, pursuing a successful academic career in marketing is really hard at times. It is essential to build in some fun, and perhaps, not take oneself too seriously. (de Ruyter)

We expand on Ko de Ruyter's comments on interaction with practitioners in the next section.

\subsection{Collaborate with Great Practitioners}

Many of our participants spoke to the importance of closely working with top marketing decision-makers. Practitioner collaboration is especially important to B2B marketing academics, as expressed by Michel van der Borgh and Selma Kadić Maglajlić:

Academia is a workplace that, we assume, most scholars are in because they are passionate about doing research and teaching others about their insights; that is, they are intrinsically motivated to improve the status quo, either by having impact in academia or by having impact in practice. Interestingly, we observe that top B2B scholars differentiate themselves by acting ambidextrously, conducting rigorous research that helps make this world a better place. This capability is something that can be learned by immersing oneself in the literature and engaging with practitioners. Understanding real-life practitioner problems inspires new research projects, but only with sufficient understanding of the extant body of knowledge it is possible for scholars to adequately frame these practitioner problems and develop new research projects and solutions. As such, B2B marketing scholars are not only passive observers of phenomena but also active designers of desired futures. This 
approach goes beyond scanning the "future research" section of published articles because it helps to go beyond the thinking frames of other scholars and lead to novel and relevant insights. This implies that B2B scholars have to build close relationships with practitioners directly or indirectly. Building relationships is based on three components: benefits of exchange, costs of exchange, and trust between partners. Therefore, in our experience, scholars should not narrowly focus only on the goal of obtaining data, but also work hard to deliver to companies, for instance via concrete and valuable methodological skills, good ideas, and state-of-the art academic knowledge. Establishing trust is crucial, for instance, by investing a serious amount of time and effort in understanding the company, becoming part of the team, and acting as a good partner. Without this trust, no sensible practitioner will share unique insights and data. The great Michael Jordan was right in claiming that "talent wins games, but teamwork and intelligence win championships." (van der Borgh and Kadić Maglajlić)

A key aspect of the above comment is ambidexterity, and B2B marketing academics are in a unique position to deliver great value to practitioners if they can truly be ambidextrous, that is, to combine their wide knowledge of the extant literature with a clear understanding of the most pressing problems facing decision-makers. How, then, can the academic strengthen these critical ties with practitioners? We begin with Ajay Kohli's actionable recommendations:

Another thing that helped me greatly was interactions with practitioners in the $\mathrm{B} 2 \mathrm{~B}$ world. These interactions occurred in various ways: (1) a graduate course team, taught with practitioners and other faculty involving, among other things, living cases of their companies, (2) full-time company 'internships' as a junior faculty member, as well as a chaired professor, (3) MSI conferences, and (4) guest speakers in my classes. Through these practitioner interactions, I learned about issues on practitioners' minds, and the language they used to talk about those issues. I also obtained data for research - both in stand-alone ways (e.g., surveys), as well as in more engaged ways (e.g., interviews, focus groups). (Kohli)

A more formal technique, but with great potential research benefit, is the establishment of a corporate research partnership. Michael Hutt speaks to his personal experiences working within such a partnership:

Since strategy research imposes challenging data gathering requirements, corporate research partnerships have assumed a vital role in facilitating numerous studies. My colleagues and I have pursued a research program that explores the interdependencies that surround the formation of strategy across functions, business units, and alliance partners, as well as the embedded patterns of influence that direct organizational buying systems. More recently, we have examined how the tenets of financial portfolio theory can be applied to enrich a firm's market segmentation and customer portfolio decisions. The success of each of these projects hinged on our ability to secure the support and cooperation of a corporate research partner. Each required access to a large number of organizational participants including senior executives. Likewise, others required performance histories of their sales force, access to their 
alliance team, or several years of data on their entire customer base. These projects are an outgrowth of a corporate research partnership initiative that the Center for Services Leadership at Arizona State University has been pursuing for over two decades. We discovered early on that corporate executives welcome strategy research proposals that combine rigor and relevance to address fundamental problems. Here are a few key lessons that I have learned across more than a dozen studies that were supported by a corporate partner (Hutt, 2008; Hutt \& Walker, 2015). First, business marketing executives are far more open to supporting impactful research studies than most faculty researchers expect. Second, the odds of securing company support dramatically increases if key executives are actively engaged in discussing a research topic or domain before the research question is sharpened and finalized. Third, drawing on the strategy dialogue with the firm, a short proposal can be developed that describes the value proposition for the partner, specifying the concrete benefits that the study will provide. (Hutt)

Douglas Lambert initiated the International Center for Competitive Excellence (ICCE) in 1992, whose initiatives included a research roundtable of academics and senior executives dedicated to improving managerial practice in supply chain management. He reports on the importance of garnering support from the senior executive community:

[I started the Research Roundtable of ICCE], a team of academics and executives, which became the Global Supply Chain Forum when I moved to The Ohio State University in 1996. The mission of the Forum is to provide the opportunity for leading practitioners and academics to pursue the critical issues related to achieving excellence in supply chain management. The advantage of the Forum was that there was time to work on well-funded, big-idea projects identified by the executive members [such as supply chain partnership] ... Since 1996, 36 publications have resulted from Forum research (Lambert \& Enz, 2017) including two books, one in its fourth edition (Lambert, 2014), and three supply chain management articles with a total of more than12,000 Google Scholar citations, one of which is the most cited article published in Industrial Marketing Management (Lambert \& Cooper, 2000). Fifteen of my 20 most cited publications are from Forum research. But, more important than the citations, the research has influenced management practice and has been delivered in week-long executive education programs on five continents. The Forum research on partnerships and supply chain management was unlike anything I had done before and would not have happened without the business executives identifying the topics as research priorities ... If there was any genius associated with my starting the Forum, it was the idea of surrounding oneself with very smart business people and listening to them. (Lambert)

The key takeaways from Hutt and Lambert's comments are that companies are often very willing to support academic research that provides value, and especially willing if senior management is involved early in the process. 


\subsection{Travel Off the Beaten Path}

Academics may occasionally find themselves in a rut, attacking familiar problems with familiar techniques, and not making any progress. At times like these, academics need to find inspiration to make a breakthrough or even to rethink the question they are investigating. Several of our contributors commented on the need to "travel off the beaten path" and to continuously self-renew by bringing in fresh new perspectives. Incidentally, this need does not diminish, even for senior academics. Here is how they do it, starting with Ajay Kohli:

I focused a reasonable amount on self-renewal, which was very helpful especially later in my career as a chaired professor. I allocated time and energy to learning about new developments periodically - by regularly sitting in on others' classes at various levels, and through self-study ... I was very fortunate to have gone to a doctoral program that encouraged thinking outside of one's comfort zones, venturing into unchartered territories, and taking intellectual risks. (Kohli)

Lisa Ellram reminds us of our responsibility, as academics, to keep learning, and that new insights can be gained by looking outside our research discipline:

My advice is to always keep learning. Read, attend conferences, and talk to people. Ask people in different disciplines questions, learn about how they do research. In what other job do you have the privilege to be paid to learn, and to learn about what you want to learn? If you do not have a curious mind, this may not be the right career for you. (Ellram)

Christian Grönroos suggests ways by which we can travel outside our comfort zone while interacting with decision-makers:

Asking the interviewees about marketing issues invariably made them talk about traditional marketing activities, whereas they did not understand the meaning of the unconventional themes in a marketing context. Hence, I had to make yet another change. I decided not to use the marketing term, but to ask the interviewees about their thoughts relating to how to get and keep customers, and what it takes to make them satisfied and willing to return. Interestingly, in these conversations the importance of conventional marketing activities, as well as of other activities, unconventional in traditional marketing models, appeared invariably. Later, in my studies of relationship marketing, another new field, I made the same observations. Thus: do not use existing models and frameworks as a starting point for your research, unless you are convinced that they encapsulate the topic you are about to study in its entirety. If they do not, you will probably generate uninteresting results with low or no relevance. (Grönroos) 
Grönroos suggests another approach: trying different methodological approaches or conceptual frameworks:

I am a conceptual researcher. However, as a teaching assistant before I started on my research for a doctoral thesis, I taught quantitative methods and experiments. My $\mathrm{Ph} . \mathrm{D}$. thesis was on the marketing challenges of service firms. This field was new and unexplored. I quickly realized that a conventional methodological approach using surveys lead me nowhere. Already then I was interested in theoretical thinking and conceptual work. Conceptually, mainly based on John Rathmell's (1974) thought that the interactions between buyer and seller seemed to have marketing implications, I had developed a tentative framework including both traditional marketing variables and totally new and unconventional themes. When formulating the elements of this framework in the form a questionnaire, I realized that it would be difficult, if not impossible for marketing practitioners to relate to the questions and turned to a case study approach instead. In Scandinavia, such an approach had already developed some interest among marketing researchers. Thus: do not use normally used, 'scientifically' accepted methods, unless you are convinced that they are appropriate for your research. Such methods will probably generate results with low validity and relevance, and of limited or no interest. (Grönroos)

\subsection{Stay Focused}

Academics need a healthy internal drive to be productive. Sometimes, the most difficult thing to do is to stay motivated, to keep going, and to maintain that internal drive to succeed at research. Matthew Robson provides his insights on the issue of maintaining focus:

What works the best of all is having a personal research culture and thus letting research truly get under your skin. That way, there is a constant drive to always get back to your research work. To misappropriate a phrase, the paper you are currently working on needs to be no more than two feet away from you at all times, even if at a particular point in time you are carrying it in your mind. Many years ago, as an early career researcher, I read the biography of the renowned Austrian psychiatrist Victor E. Frankl, a Holocaust survivor. One thing that stayed with me from his harrowing account was that when he was first sent to the concentration camp, he had an academic paper on him that was confiscated by the guards. Not realizing what was coming, he was irked by that. He was so into his research that he was not seeing clearly what was going on around him. Victor's drive to get back to his research was misguided. Yet, it is impressive, too. Irrespective of their circumstances, researchers are loath to let the scent go cold. To keep up my drive, I try to find flow in my research by treating a paper as a game that needs finishing-I am a completion nut; varying the roles I perform on papers in order to keep my skills at a high level across the board - it helps with dealing with reviewers; and varying who I work with, finding enthusiastic co-authors and learning from them as I go. I am motivated by being generous with my scholarly activities, and part of this is forging good working relationships with early career researchers. Of course, such researchers have an infectious drive to research, as well as time on their hands, and their enthusiasm and energy boosts my own. (Robson) 


\subsection{Have Fun and Celebrate Successes}

As a final consideration, remember to enjoy the journey and the destination. An academic career will bring some stress and frustration, but also genuine moments of satisfaction and even excitement. As Lisa Ellram writes, it is important to work on projects we enjoy, maintain perspective, and take the time to celebrate the successes and achievements:

In terms of focusing my research, what has worked best for me is finding real world problems that I am interested in, and that I believe would benefit from some insight, solution, and explanation ... Because research often does not go how we planned, I think it is important to find topics that I am genuinely interested in - things that excite me, and that I want to understand, not just going after a hot topic or joining a project that does not excite me because I was invited. Learn to say no when a project does not feel right for you ... In addition, I think it is very important to keep your perspective. When things do not go as planned, it is rarely the end of the world. Do not worry about how much money other people make, whether they are hitting 'better' journals than you. Compete with yourself in setting goals and focus on those. There are always going to be people doing better or worse than you are. Make your own luck by being engaged, ethical, and a good colleague to work with ... Have fun with what you are doing. Life is short. If being a professor is drudgery for you, you need to change your attitude, your focus, or your job! You will be happier for it, as will everyone around you. (Ellram)

In sum, our contributors provided much guidance to young scholars, gained through their own experiences and successes. In the next section, we review their thoughts and comments on what an early-career academic should avoid.

\section{WHAT DOES NOT WORK}

We have distilled our contributors' thoughts on mistakes to avoid into the following five sub categories, each of which we discuss next:

- Working with colleagues who lack enthusiasm and aspiration.

- Working on problems with no practical relevance.

- Mimicking other academics.

- Having too little time.

- Handling reviews the wrong way.

\subsection{Working With People Who Lack Enthusiasm and Aspirations}

We are fortunate as academics in that we usually have much freedom in choosing colleagues with whom to work. As noted earlier, we have many options by which we can connect with colleagues. It makes sense, then, to choose wisely, 
to increase the chances of successful research output, and also to enjoy the process more. Ajay Kohli's thoughts follow:

I have tended to work on a variety of topics, simply because I find them interesting, and with a relatively broad set of authors. My experience has been that projects that were fun to do and resulted in impactful outputs were with co-authors who shared my enthusiasm for a topic, aspiration for the work, and work rhythms. Contrarily, when these qualities were absent, the projects tended to flounder. (Kohli)

\subsection{Working on Problems With No Practical Relevance}

As mentioned earlier, most of our contributors stressed the importance of working on problems of pressing importance to the practitioner audience. Ko de Ruyter writes eloquently about how one can maintain relevance to the practitioner community, while still achieving a high likelihood of academic success. His argument centers around considering the impacts of new developments on practice, rather than simply reporting familiar results. He explains:

I have found that in the field of B2B marketing, theoretical and practical contributions are required to be balanced. Too many times I have tried out unnecessarily complicated theories in $\mathrm{B} 2 \mathrm{~B}$ projects, which often resulted in unreadable papers that did not address real-life problems, let alone come up with actionable solutions. A very helpful criterion that I now use is to try to establish a seamless storyline that departs from a real-life B2B challenge all the way to a relevant theoretical paradigm and back. I have found that if this process is seamless, it increases the chance of success. Also, in an extended cooperation with an industrial marketing company I found myself presenting 'flat-line', same old, same old results to the board year after year. I guess that corroboration of findings across time is an important criterion in academic and applied research. However, it is equally important to spice up long-standing research collaborations with new developments or gauging the impact of new technologies alongside it. I have learned that just reporting the same results across time does not work for engaging the interest of stakeholders and, to be honest, journal editors. (de Ruyter)

Another way to ensure that a problem has practical relevance is to get enthusiastic support from senior management. Michael Hutt notes that poor positioning of a research project when seeking practitioner support will leave the impression that the research will have no practical relevance and will result in no management commitment, even in a case where the results are eminently publishable:

In seeking corporate cooperation and funding for a project, I have encountered far more difficulty in those situations where a research proposal was submitted in the absence of a thorough discussion with key executives in the firm. For example, our research team was enthusiastic about a project that applies modern portfolio theory (from finance) to the customer relationship management process (Tarasi, Bolton, 
Hutt, \& Walker, 2011). We presented the proposal to a few potential corporate sponsors who politely passed. We failed to nail down the managerial benefits. Upon reflection, we positioned the study in the area of market segmentation and customer profitability, engaged in a lively discussion with a corporate sponsor, and secured support and a high level of cooperation from a large transportation services company. While representing a long journey, each member of our research team views the customer portfolio project as their career article-a Maynard Award winner at the Journal of Marketing. (Hutt)

Ko de Ruyter affirms that many early-stage academics may fail to recognize the importance of establishing ties with the practitioner community. While this may be a career mistake for many business academics, it is especially troublesome for B2B marketing researchers, who almost by definition are working on problems of managerial relevance. He also provides a strategy for how one can jump-start a closer relationship with practitioners:

At the start of my career, I did not spend time talking with senior business marketing professionals. I soon realized that such conversations would have better informed my teaching and my research. Being in a tenure track, I was too focused on research and publishing in international journals. When I did talk to professionals in companies, I realized this was a shortcoming. So, after the first five years or so, I started to actively pursue giving seminars and talks for practitioner audiences. I also volunteered to take on executive teaching, which was frightening at first and very rewarding later. (de Ruyter)

\subsection{Mimicking Other Academics}

An early-career researcher may be awestruck by a world-renowned academic, or highly impressed by a doctoral seminar lecturer or senior adviser. It is good to try to learn from the success of those that have gone before. One, however, must not fall into the trap of copying them, right down to their teaching styles. We are our own individuals with our own strengths and characteristics; we should recognize these, and build on these, to develop our own individual styles. In the long run, we want to establish our own identities, rather than being a virtual shadow of someone else. Ajay Kohli explains:

When I was a junior scholar, I admired many of our accomplished colleagues for the way in which they went about their work. I tried to mimic these established scholars in an effort to perform at higher levels. For example, I tried to mimic the teaching style of a senior professor I admired greatly. However, that did not work, and actually was a frustrating and counterproductive experience. I learned the hard way that you have to develop your own style, and be authentic to who you are at your core. (Kohli) 
This idea extends to our research as well. Christian Grönroos relates an anecdote about the hazards of using a methodology, which he found to be impractical and, ultimately, not that interesting to him:

When doing conceptual research, you may still want to ground it empirically as part of the theory development you are doing. For me, attempting to do quantitative studies when working on a conceptual topic has turned out to lead to meaningless results. I remember when I once was determined to do a quantitative study to support a conceptual piece of research on the marketing of consumer and industrial services. I developed a questionnaire, but when I tested it on a former colleague of mine working in business, his reaction was: "Why do you do it like this? Why do you not discuss the themes with people instead?" I followed his advice, and after that, I have stuck to what interests me most, namely conceptual research and theory development and qualitative research. (Grönroos)

\subsection{Having Too Little Time}

Academics, like everyone else, need to consider time management, which of course is easier said than done. Ajay Kohli suggests making a plan each evening for the next day, and sticking to it, to avoid being distracted by other things that consume our available time:

I know of several very accomplished scholars who develop a plan for each day, and follow the plan diligently. However, I could never bring myself to do that. I worked hard on a project either because I was thoroughly engrossed in it or because I needed to meet a deadline imposed by co-authors, journals, or promotion systems. I believe it can be useful to develop a plan each evening for the next day, and stick to it. (Kohli)

Matthew Robson notes that we may have less time available, the further we go into our career, due to the many demands on our time, so it is never too early to develop sound time management skills. In fact, the realities of academic writing may require us to set aside — and vigorously defend — lengthy blocks of time to get things done:

Time management is a tricky issue, and I have seldom got this right. As an early career researcher, it was easy. I recall spending two leisurely days reviewing a paper for a decent journal. If I did that now, all sorts of plates would be crashing onto the floor. One issue is that classroom and administrative duties have short-term deadlines, while journal papers can take as long as they take. Indeed, stronger papers have longer time-frames of development than weaker ones. So it is always the higher-level research work that gets squeezed. Probably, over the years, I should have come up with defensive ways to prioritize top-level research; but that is not exactly commensurate with academia within UK institutions (e.g., TEF, REF, and accreditations) and the best way to nurture and build the marketing academy. Finding a way to devote long blocks of time to papers is incompatible with modern 
expectations of presenteeism, and our always available and responsive e-mail culture. A former colleague of mine works on the basis of two-week time blocks on top papers, and he has a set of offensive and defensive mechanisms geared toward carving out these blocks. (Robson)

We can be our own worst enemies if we are unable to say no to a time-consuming responsibility. Project management skills can be adapted to the academic career in order to avoid bottlenecks, keep focused on projects that are consistent with one's objectives, and get papers submitted to top journals. Michel van der Borgh and Selma Kadić Maglajlić explain:

One of the most challenging aspects of being a scholar is managing your time. These days, junior faculty are asked to be like 'ten-trick ponies', as they need to excel in a multitude of domains including research, teaching, attracting funding, getting international exposure, and being a good citizen. As a result, some junior faculty tend to freeze or decide to pursue a different kind of career. Reflecting on our personal experiences, it became apparent that one tries to navigate the academic landscape, and that it is crucial to learn to prioritize activities, projects, and opportunities without becoming a jerk. Practically, it implies that you need to focus on projects that are intrinsically motivating, build on your strengths, and help you reach your goals. Not doing so will lead to situations where you spend most of your time on projects that are not gratifying, do not help build your profile, and drain energy. A related aspect is that it is important to keep attentional focus and not be occupied with too many things at the same time. Especially with tough or daunting projects and activities, it is easy to procrastinate and flee into new projects or other activities that do not help you move forward. Therefore, it is important to avoid this situation and to ensure to deliver a project before you start a new one. From personal experience, we know that it can happen that projects - although almost finished — stay on the shelf for a long time before being submitted to a journal. Project management skills and applying tools and heuristics from operations management can be useful to prevent this. One such heuristics is to ensure that projects flow to the pipeline as fast as possible and to prevent bottlenecks. If bottlenecks do occur (e.g., projects are not progressing) you need to take action by either killing the project, asking for other scholars to help out, or by prioritizing it yourself. (van der Borgh and Kadić Maglajlić)

Finally, Douglas Lambert reminds us of the scarcity of time, and hence the need to use it on research with maximum impact. This means going slow and steady, always working on top projects, as this strategy will more likely result in academic acceptance and recognition.

There is growing awareness that the majority of research produced in business schools lacks relevance and benefits no one but the authors who are given pay increases and are promoted for generating research that "infrequently impacts practice, often falls short of standards for credible research, and fails to create a strong return for the investment" (Glick, Tsui, \& Davis, 2018). My advice to younger colleagues is to work on fewer, better projects, or as my mentor once said in a Ph.D. 
seminar: It is important to "slow down and get it right." Time is the one thing that we all run out of too soon and it happens far faster than most of us ever expect. Why waste such a precious commodity? Rather than focusing on the number of articles and where they are published, Nobel Laureate Bruce Beutler (2017) offered the following advice: "If you do good solid work, consistently, you will be recognized." His colleague, Nobel Laureate Joseph Goldstein (2017) added that: "Any great paper will be found and read." (Lambert)

\subsection{Handling Reviews the Wrong Way}

All academic researchers experience rejection from top journals; it is impossible to avoid. As with any other kind of setback, what matters is how you handle it and move on. A specific challenge is when a reviewer appears not to understand the research, or whose opinion might just be totally wrong. Lisa Ellram reminds young academics not to be disappointed, but to determine how best to proceed.

Sometimes I like a project I am working on better than the reviewers. That is frustrating when you cannot find a good home for your research, and you really do not understand why not. Unfortunately, I do not have any insights there except do not let it discourage you from moving ahead ... Another issue I have encountered is having inappropriately assigned reviewers who I think do not understand a topic or a method that I have used, and make suggestions that indicate a lack of understanding. A common problem when dealing with case research is reviewers who do not believe that companies are as dysfunctional as they are described ("Why would anyone do this ..."- exactly! That is why this is interesting to study ...). I have also had reviewers of case research that indicate that my respondents are lying. Clearly, that person should not be assigned to review case research, but they were. In these cases, I want to reach out to the editor and ask him/her to reconsider the reviewer. I have not done this in the past because I do not want to appear to be asking for favors. But it is something that I think I should do that will help other researchers as well. However, as a reviewer or associate editor, I do specifically comment when I see reviewers who appear to not to understand the research, the method, or maybe who have just not read the paper carefully. I will feel free to disagree with them and comment on why and try to do so in the most constructive way possible. I would like to help develop more constructive and thoughtful reviewers. (Ellram)

\section{DILEMMAS - AND WHAT TO DO}

Our contributors identified a range of dilemmas - difficult situations without a clear solution - that early-career academics face. We have identified several of these dilemmas, and distilled the advice offered by our contributors, in the following section. Our discussion is organized into these sub-categories:

- Sequence of authorship.

- Stand up for what you do. 
- Research that does not 'work'.

- Future pipeline.

\subsection{Sequence of Authorship}

On a co-authored paper, who should be listed first? It is something to consider, especially if author order could be taken as a signal of relative contribution. One simple convention is to use alphabetical order (and noting this in a footnote), but there is no one-size-fits-all solution. Ajay Kohli provides some perspective and recommendations:

A dilemma to which I have not found a great answer to this day is the issue of author ordering on a co-authored paper. In a well-functioning team, members exchange ideas freely, and the goal is to produce the best ideas and execute on them. In such teams, members tend not to closely monitor who is making what contributions over the multiple years it takes to develop and publish a research project. Indeed, if co-authors spend time and energy on tracking who is contributing what, it is likely to take away from the fun of collaboration, as well as the substance of research. As such, in many cases it is seldom clear who contributed how much to the final product. A solution I settled on early in my career is to work with co-authors I really liked, and who had comparable competences and aspiration levels. We worked on multiple projects, were fully engaged in developing all projects, but alternated lead authorship concurrent with primary responsibilities for developing first drafts of papers, and post-review revisions. This worked quite well. Another approach I used was simply to toss a coin to determine authorship. In yet other cases, I let my co-authors decide the author ordering. (Kohli)

\subsection{Stand Up for What You Do}

As marketing academics, we understand the value of positioning our research for the intended audience (editors, reviewers, and academic peers). This usually means a clear statement of research objectives in the introduction, a summary of the theoretical and managerial contributions in the conclusion, and an effective abstract. If one is challenging the norm (for example, proposing a very new conceptual model or methodology, or using a conceptual approach in a journal that usually publishes empirical studies), it is especially important to position well, so the reviewers and editor will see and understand the potential contribution, and in some cases to challenge a negative outcome. Christian Grönroos explains, and provides a solution to this dilemma:

In the field of marketing, journals sometimes claim that they also welcome conceptual papers. However, marketing journals mostly prefer empirical papers using quantitative methods. When doing research on a new topic or approaching a topic in a new way, and especially if you do it conceptually, which I often have done, it is normally more demanding to convince reviewers and editors about the value and 
contribution of a paper. Compared to doing empirical papers you have to be more persuasive. Earlier in my career this was less of a problem. I have a feeling that journals were more open-minded then. Once, I had submitted a paper on relationship marketing, which the reviewers turned down. The paper took a new approach to the field, and I honestly considered it solid and its contribution relevant. I wrote to the editor and said that I thought the reviewers did not really understand relationship marketing. The paper was eventually accepted. I had to do that another time, as well with a paper on marketing communication. However, if doing this, you have to be convinced that you have a good case. ... I have also found that submitting papers to special issues may work well. A special issue is focused on a particular theme or field and, in my experience, both editors and reviewers tend to be more open to unorthodox approaches. (Grönroos)

\subsection{Research That Does Not Work}

What happens if the many months of research yield few interesting and publishable results? As academics, we naturally focus on article publications, yet we may be able to get much mileage out of unsuccessful or marginally successful research in other ways. Lisa Ellram provides some recommendations:

One dilemma we all face is when we conduct research that does not get the results we hoped for, and the results were not interesting enough to get published anywhere we want to publish. I do not think that can be prevented. I try to use those experiences as examples when I am teaching and have even created case studies or class scenarios from some. I also use these for examples when I give talks. No learning is wasted. (Ellram)

Those results that were just too narrow or uninteresting for the top academic journal in your area might be a great example to use in MBA classes for many years!

\subsection{Future Pipeline}

Early career academics know the importance of establishing a pipeline. A clear path to future research is always viewed favorably in promotion and tenure decisions, as is a healthy stream of works in process. But what exactly is a pipeline, and what should a young academic be doing to prepare a pipeline for continued success? Matthew Robson suggests taking a broader view of the meaning of academic pipeline:

An enduring dilemma for me has been which theories, methods, and fields to work in. Making decisions about your academic skill set and how to evolve this logically is crucial. You need to keep updating, but where do you draw the line. Unfortunately, academics are like a flock of birds - feel free to come up with your own collective noun!-in that they move from one hot topic to the next. Substantively, from channels, to entrepreneurship, to services, to digital, to ... Methodologically, from sampling bias, to common method bias, to selection bias, to omitted variable bias, 
to ... For sure, being at the vanguard is the best thing for publishing and citations. However, marketing management considerations kind of get left behind. Managers need channels studies (e.g., look at the effect Brexit is having on supply chains and how quickly their arrangements unravel under conditions of uncertainty). Further, they do not want to be fed a diet of marketing papers with the level of methods precision needed to put a rocket on the moon. Our discipline is marketing, and while rigor is important, it has its place! (Robson)

A related question is whether to continue on an established pipeline, or to explore research possibilities in new and trending topics. There is value in both, so how should a young academic allocate time across research streams? What is the trade-off between opening up new research horizons, and jumping onto the hottest new business topic which turns out to be a short-lived fad? Here is some perspective from Michel van der Borgh and Selma Kadić Maglajlić:

The central dilemma in journalism is that "you don't know what you don't know." Probably this also can be said about the future of academia and our role within this discipline. Practical questions that arise revolve around "what type data will be preferred (i.e., primary survey data versus company data)?," "what methods and data analysis software will become mainstream?," or "which topics should I focus on?" We always reflect on these questions, and it is a never-ending story of which we only understand the answers in hindsight. Indeed, we reflect on whether we should embrace new trends (e.g., big data or social media) or remain loyal to our current research topics and practices, which perhaps are less trendy (salesperson behavior and customer loyalty). Although we cannot predict the future, it is clear that interesting research ideas will remain top priority for journal editors. The same goes for investing in new projects with new co-authors or building upon existing relationships and projects. Although the latter may be more effective and efficient, the former definitely will open up your horizon and enable you to learn new ways of working, irrespective of the outcome of the individual projects. Again, this relates to ambidextrous challenges or trade-offs, but in practice it probably is needed to navigate between both options. (van der Borgh and Kadić Maglajlić)

\section{ADVICE TO EARLY-CAREER RESEARCHERS}

In this next section, we identify some themes regarding career advice which emerged in our discussions with our collaborators. We organize these themes into the following sub-categories which we explore next:

- Regularity.

- Literature.

- Passion and uniqueness.

- Collaboration.

- Thoroughness.

- Criticism. 


\subsection{Regularity}

Many contributors stressed the importance of having a work routine, and to invest the time required to accumulate a broad knowledge of the literature, especially early in one's career. Ajay Kohli explains the link between routine and research excellence:

Perhaps the most important thing I would say is to develop a work routine, and stick with it as a matter of priority. Good research requires creativity, and flashes of brilliant insight do not just happen. They require prior preparation and nurturing, which comes much more easily if one has a set work routine. It may be five days a week from 7:00-5:00, six days a week from 8:00-6:00, or seven days a week from 9:00-5:00, or whatever. The important thing is to focus on the work you are doing day in and day out. Research excellence requires regularity. (Kohli)

Matthew Robson notes that a reading routine yields many dividends, especially later in one's career:

A former dean of mine would come to lunch, and he would ask us if that morning we had "pushed back the boundaries of knowledge." I would answer obsequiously with: "yes, of course professor." But really I would think to myself, 'not quite', as I had spent that morning reading and only two or three papers at that. Yet, it is because of this legwork that ultimately I became an authority in specific fields. So my advice is: do not be in a hurry. Put in the hard yards, as these can keep paying back, even 20 years later. The more senior you are, the more you are pulled in every direction administratively and the less time you have for pure research activities like reading. I seldom read academic work simply for the sake of reading. A department chair I know, when asked the "how can the school better support you?" question in his annual appraisal paperwork, answered: "give me a time machine." So make sure you invest your time well during your formative phases. This ... is your time machine. (Robson)

Having a routine, however, is not the same as being blind to emerging opportunities. As Ko de Ruyter notes, following one's curiosity might lead to a change in research direction that pays off in terms of published output:

Most importantly, be aware of the fact that life and career tracks may take unexpected turns, and that it is important to recognize opportunities when they present themselves. Equally, it is important to realize that a career path may change because your own interests may change as you grow professionally and personally. Conducting research should ultimately be intrinsically enjoyable, and while people may keep emphasizing that you need to take an agenda-based approach, keep focused on the pursuit of your own curiosity, even if that means changing direction every now and then. Finally, it is important that you celebrate success with your colleagues and your loved ones, because a research career is not a solo journey. (de Ruyter) 
Finally, one must never forget that the process from research idea to published paper is a long one. Michel van der Borgh and Selma Kadić Maglajlić provide advice on how to avoid frustration, by setting shorter-term goals, enjoying non-research related activities, and staying positive:

All in all, it is important that you are happy when doing your work. Every time it is easy to become too occupied with targets and stressed out about not reaching them. Interestingly, we experienced that the situations where targets become less important-for instance because they look unattainable-are often the situations where everything started going smooth and materialized as initially hoped. Although the effect is partly due to the enormous initial investment, it also indicates the importance of relaxing and cheering up. In addition, being a scholar implies that it needs time before projects will land in journals. So, be sure to engage in activities like teaching or mentoring that are rewarding on the short(er) term. It helps to keep sane. (van der Borgh and Kadić Maglajlić)

\section{$5.2 \quad$ Literature}

To be successful at research, and to provide value to the practitioner community, it is imperative to stay current with the literature. The number of new articles each year is staggering, and continues to increase. One needs a strategy in order to avoid being inundated. Michael Hutt provides valuable suggestions on how to stay afloat:

Across a research career, a strategy scholar can secure an edge by developing a habit of regularly scanning important themes and interesting theoretical perspectives across disciplines from psychology and organizational theory to finance and strategic management. Among my favorites are Administrative Science Quarterly, Organizational Science, and Academy of Management Review. By lending a fresh conceptual focus or a novel methodological twist, I can identify several of my published articles where an Administrative Science Quarterly article provided a distinctive springboard and differentiating feature that enhanced the contribution. Rather than a targeted search, the approach here is to review article titles, scan through selected articles, and then explore more deeply the one or two articles that relate to your research program, now or potentially in the future. By investing some idle time, say a few hours a month to this exercise and making it a regular habit, a wealth of unique conceptual and methodological ideas accumulate over time and form a portfolio of tools that can be called upon to advance your research program. (Hutt)

While Hutt is writing specifically about strategy research, his comments can be applied to any discipline, and other top journals may be substituted depending on one's research interests. 


\subsection{Passion and Uniqueness}

Many academics choose this career because they are passionate about studying a particular topic. Ajay Kohli reminds us never to lose this passion for one's work, and to pursue research obsessively, saying no to other projects, which we do not feel passionate about:

Another suggestion I would offer is to work on topics about which you really care. If you have yet to develop a passion for something, explore things that pique your curiosity to see whether you develop a strong interest in it. You are far more likely to develop useful new (publishable) insights on a topic if you are obsessed with it. Learn to say 'no' to working on topics that you do not think you will really enjoy, or are not as high on your list of priorities. The odds are very high that you will have many more ideas than you will have time to work on. So choose well, and dig deep. (Kohli)

Many companies, including Google, allow their employees to work on their own pet projects on company time and provide support for such activities. This practice encourages employee creativity and may result in discoveries that greatly benefit both employee and company. Michel van der Borgh and Selma Kadić Maglajlić suggest that academics can profitably apply a similar policy to their own research:

Be selective in projects and try to understand what your unique selling point is. For example, Warren Buffett's 5-Step Process for Prioritizing is one way to do this. This prioritization is a continuous process and one that never ends. Following practitioner heuristics, we think it is important-given the current pace of progress in technological advancements and analytics - to reinvent yourself every three years or so. This also implies that you need to take time (say 20 percent) to make this change. Learn from, for instance Google's 20 percent time policy, to allow yourself to work on 'pet' projects for 20 percent of your time. It also helps to stay motivated. (van der Borgh and Kadić Maglajlić)

Christian Grönroos writes about the importance of passion in one's work, and reminds us of the importance of thinking outside of the mainstream:

In an anthology consisting of career reflections by service marketing pioneers (Fisk, Grove, \& John, 2000), I characterized my research approach quoting Frank Sinatra: "I did it my way." In my view, this is a good piece of advice to any young researcher. Dig where no one else has done it before, and you may make a quantum leap. Break out of the box, and you will find that there was no box, only a random construction by the research community. Following the mainstream may be an easier road forward, but probably it will not generate outcomes that are remembered. ... In an autobiographical article (Grönroos, 2017, p. 278), I wrote the following, which I have told generations of researchers: "Only if an extant theory or model can be built on in a meaningful way should it be used as a starting point. Only if what 
you are studying is known well enough to respondents such that they consistently understand your questions and scale points, and do this in the same way as you intend them to be understood, can you use conventional data-gathering methods and statistical analyses. ... A researcher has to be strong in his or her faith. I always advise students and post docs to believe in themselves and in what they are doing and to listen to comments, but unless they realise there is a better way to do it, never to let themselves be talked out of what they believe in and out of the methodological approach they consider fit for their study. Sometimes, advice from other persons is appropriate, but not at all always." (Grönroos)

As Grönroos says, we need to be passionate in what we do, and to stick with our research ideas which we believe in. Similarly, we need to be able to communicate this passion to our students as well, and this requires that we think about how we can translate our research so it is meaningful and even inspirational for students. Ko de Ruyter provides his perspective:

Learner expectations across different levels seem to be going up continuously. There is much emphasis on delivery, formats (e.g., check all the boxes when it comes to feedback, feedforward, formative and summative assessments) and seemingly less of an emphasis on expertise. Administrators seem very focused on meeting student preferences, rather than shaping them. One of the dilemmas is that this seems to widen the gap between what we do as researchers and as teachers. I stubbornly try to hold on to meaningful and research-driven content, and one of my standard responses to student feedback ("too much theory") has always been: "it's an academic degree" or "it's your last opportunity to learn about this." I am still experimenting with different ways of making our research accessible to students, and I am happy to see that an increasing number of journals develop material for classroom discussion to support this. (de Ruyter)

\subsection{Collaboration}

Douglas Lambert reminds us of the importance of choosing the right collaborators, which will allow you to build a high-impact research stream:

Our business is a team sport; pick your co-researchers and co-authors well. Choose colleagues who share your work values, build upon your strengths, and offset your weaknesses. Develop research streams instead of working on opportunistic unrelated papers. A research stream is not a collection of unrelated articles on a particular topic, but research that builds upon your prior work. We all know academics who have written many articles on a wide variety of topics, but if you close your eyes and try to picture the person you cannot do so ... What are they known for professionally beyond the fact that they have written a lot of articles? Publish in a small number of outlets directed towards your selected audience(s) so your name appears often enough that people take notice and associate your name with a research stream. Give up short-term gains for bigger payoffs in the long term. (Lambert) 
We can also elaborate on effective ways to broaden our reach to collaborate with an exponentially larger number of colleagues. Ajay Kohli recommends offering to review for journals, which is a good way to build visibility and reputation with editors:

Get involved in reviewing for journals and conferences early in your career. Reach out to journal editors and conference track chairs with an offer to do reviews for them. You learn a lot from the process, and get to contribute back to the community. (Kohli)

Lisa Ellram suggests other effective strategies (building ties with school colleagues and networking at conferences), and reminds us of some of the benefits of getting to know editors and other senior academics:

If you do not have people to work with, read the work of people in areas you are interested in, go to conferences and meet them, ask them if they would be willing to collaborate, or suggest others with whom you might collaborate on your topics of interest ... Serving as a reviewer can help you understand and improve your own research and help your visibility. Associate editors and journal editors may be asked to do external reviews of your dossier for promotion and tenure purposes. Providing constructive, timely reviews is helpful to create a favorable impression. If you choose to serve as a reviewer, be a gardener, helping the authors improve their work, even if it is weak. Do not view your role as primarily a gatekeeper and critic, to show the associate editor or editor how smart you are. Be reasonable, and help people improve even if they will never know who you are. There are real people behind every paper you review. Have standards, but be kind ... If you have choices in your job opportunities, find work in a collegial, supportive environment. Your life will be more pleasant, and you will not waste so much time dealing with personalities. Find a workplace that values the type of research that you want to do. Find topics that you love to work on, and people you like to work with that do their fair share of work on a timely basis. (Ellram)

\subsection{Thoroughness}

It is important to have a good start to a research program: to build a conceptual model that will make a theoretical contribution to our research stream. As Michael Hutt notes, it is critical to be thorough at this early stage. Editors and reviewers are likely to be more accepting of a paper addressing a strong and high-potential problem, and more willing to recommend revise and resubmit. He elaborates:

The essence of a strategy research program revolves around selecting interesting and important research questions that may reveal valuable and significant insights for theory and practice. Importantly, then, the choice of research questions constitutes one of the most important decisions that a researcher makes. Consider the cycle time that an empirical study follows from the idea stage to final acceptance 
of a paper at a premier journal. A minimum of two or three years can easily be consumed in designing and executing the study, analyzing results, crafting the paper, and refining the paper through multiple rounds of the review process. To this end, critical attention should be given to the idea phase of the research process and one should insist on choosing only those research ideas that pass a rigorous test of theoretical and managerial significance. If a timely and important problem frames the paper, I find that reviewers and journal editors are more tolerant of some shortcomings (e.g., sample size) and appear more willing to offer the opportunity to undertake a major revision. In reviewing a potential research question, consideration should be given to identifying core hypotheses, assessing the feasibility of developing a vigorous research method for testing them, and, above all, thoughtfully evaluating the degree to which the proposed project fills a gap in the literature and advances marketing theory and practice. Ultimately, the choice of perhaps a dozen or fewer research questions shapes the identity and promise of a scholar's research program in the discipline. (Hutt)

Hutt also acknowledges the importance of coming 'full-circle' in the manuscript, writing a strong conclusion that shows how the research objective stated in the introduction was achieved. Introduction and conclusion thus become bookends for the manuscript, effectively positioning it and reinforcing its contribution to the literature stream. Here is Hutt's view on the benefits of a thorough introduction and conclusion:

An engaging research question simplifies the task of crafting what I believe to be the two most important sections of a manuscript - the introduction and the conclusions sections. If pressed, reviewers and journal editors alike will confess that high-quality papers with publication appeal provide a strong signal of merit that is evident in the first five to six pages of the introduction to a paper. Here, the author has established the importance of the topic, anchored the study in the literature, defined the purpose of the research, and concisely identified the specific contributions, as well as the gaps in the literature that will be filled. Moreover, high-quality papers deliver on the promise that was foreshadowed in the introduction by clearly communicating the contribution of the study in the conclusions/implications section. I believe that the odds of success for a major proportion of the papers submitted to leading marketing journals could be enhanced by devoting special effort to (1) strengthening the value proposition for the paper with a more compelling case in the introduction and (2) offering a detailed closing argument that illuminates the contributions and their significance to theory and practice. (Hutt)

\subsection{Criticism}

As academics, we need to get used to criticism. Top journals have very low acceptance rates, and reviews can be discouraging. It can be especially disheartening for an early-career academic to receive harsh reviews of their work, and it is not much consolation to learn that it happens to everyone in academia. One strategy to increase chances of success is to get the research 'out there': 
present at departmental brown-bag lunches and local conferences, solicit comments from colleagues, present at a national or international conference, and keep improving until the paper is ready for submission to a top journal. Ko de Ruyter offers his thoughts:

Getting research published is hard, and surely it is not getting any easier. Even though editors keep writing editorials that encourage reviewers to be constructive, the reviewer default position still seems to be to reject papers. Over the years, collaborators from other disciplines have repeatedly told me that they were baffled by some of the harshness of comments that they encountered in marketing journals. My advice therefore to starting academics would be to brace themselves for this and develop a routine that helps you cope with some of the negativity that seems to be related to the review process. Also, try to become an active part of specialist conferences and research groups. You will learn about the discourse that journals expect you to adopt and get a better feel for those ideas, problems and approaches that are appreciated within a specific sub discipline (such as B2B marketing). This will be picked up by review teams and hence your paper will fit in better. (de Ruyter)

\section{CONCLUSIONS}

Both authors of this chapter were struck by the sage advice offered by the contributors, and were encouraged to reflect on their own careers. A fitting way to conclude, then, is with a brief statement from each of us.

The role model for my academic career has always been my dissertation chairperson, Roger Calantone. Many of my colleagues' comments reminded me of what I learned from Roger's example as a junior academic. He had a slogan written on the blackboard in his office: "Do things that lead to the top!" This is invaluable advice, as it has led me to stay focused on projects that have advanced my career and to say no to other opportunities, which did not fit. I also learned from Roger that all papers find a home. A blown research project might indeed be a tremendous case example for use in a graduate class - and the students are impressed with the occasional war story from a top company. He also reminded me to keep a drawer of research ideas for which there may not be time today; that way, when the paper I am currently working on is finally sent off for review, I can get started immediately on something else. Roger was also an expert at handling bad reviews. As a very junior academic, sending my first papers off for review, I would become distraught when I received what I thought were brutal comments from reviewers. Roger had this way of looking at the reviews and putting them into perspective, saying something like "Well, Point 1 is valid and we need to fix this. Points 2, 3, 4, and 5 are easy. On Point 6, the reviewer is wrong. No worries. We will get it done." Just hearing these words from a senior person with a seriously impressive research record provided reassurance and confidence to an early-stage academic. Roger also inspired me to do research that has practical significance. He once said that we, as business academics, should be able to take a research conference presentation, make a few positioning changes, and deliver the same presentation to an audience of senior executives, who would feel they learned something of importance. I never forgot this, and this advice has inspired and focused my research in product innovation and 
business-to-business marketing. I also learned the value of doing thorough, critical reviews whenever asked. This caught the attention of Tom Hustad, Editor-in-Chief of Journal of Product Innovation Management at the time, whose support helped me immensely in my later career. Finally, the comments about not mimicking other academics rang very true for me. I could never be Roger Calantone in the classroom; we have very different teaching styles. Instead, I strove to find my own style which is true to me and my personality. He once told me about what it takes to be a good classroom teacher, and he stressed that I should "be a character." I took this to mean: be yourself, bring your own personality, don't try to be someone you are not, show your human side, and be memorable. (Anthony Di Benedetto)

The single most important piece of advice I can offer is to collaborate with the right people. The reasons are obvious and numerous. You have different skill sets. You encourage each other. You have the same goal of having that $\mathrm{d}^{* * *}$ paper accepted for publication. And, because you know each other, you won't let each other down; in contrast, you will work hard, and you will celebrate together. In a similar vein, it is equally important not to work with colleagues where you do not 'click' or at universities where research is undervalued. As head of department, I have invested much time and money in setting up an ecosystem that facilitates and supports collaboration between faculty, an ecosystem consisting of supportive and topically driven research clusters that have their own research budgets; brown-bag sessions; visiting academics presenting their research in department meetings; honorary professorships; individual research budgets (for research purposes) that are topped up when individuals publish in prioritized journals; and a research-funding writing club, among other initiatives. I have also considered the composition of the department's faculty and hired faculty to develop new research fields or further strengthen existing ones. When it comes to specific research projects, as a researcher back at University of Auckland and Eindhoven University of Technology, I learned to focus on fewer, but better papers, and also that without a solid introduction that would discuss why this research was worthwhile to undertake (i.e., what do we know, and what do we not know, and why is it important to know-theoretically, methodologically, and/or managerially-what we currently do not know), the chance of having the paper accepted for publication is not high. Indeed, oftentimes, reviewers and editors will not continue reading beyond the introduction when they do not recognize any value in the research. And speaking of papers, the key step is to be invited for a revision. When that is the case, one has (and especially when one has submitted to a good journal) clear comments, suggestions, and directions from the reviewers and possibly the editor that should guide the revision of the paper. Equally important is to have enough creative space for working on one's research. It is no good if you are inundated with teaching, administration, and meetings. I have also often learned much from looking at other colleagues to see what they have done, and what has worked for them. When you compare yourself with others, you realize what you should continue to do, what you should change or stop doing, and what you should start doing. Finally, some colleagues are afraid of reaching out to top scholars. They should not be; top scholars - for the most part - are friendly and interested in collaborating. Thus, the best thing is to approach colleagues with an interesting project (i.e., why is this project worthwhile), and what is in it for you and me (i.e., how will the collaboration be). (Adam Lindgreen) 


\section{REFERENCES}

Beutler, B. (2017). Interviewed in "The Research Counts, Not The Journal: Views from Nobel Laureates," at: https://www.youtube.com/watch?v=6MQ8R0OyvyQ.

Fisk, R.P, Grove, S.J., \& John, J., eds. (2000). Service Marketing Self-Portraits: Introspections, Reflections, and Glimpses from the Experts. Chicago, IL: American Marketing Association.

Glick, W.H., Tsui, A., \& Davis, G.F. (2018). The moral dilemma of business research. $B i z E d$, May/June, pp. 32-37.

Goldstein, J. (2017). Interviewed in "The Research Counts, Not The Journal: Views from Nobel Laureates," at: https://www.youtube.com/watch?v=6MQ8R0OyvyQ.

Grönroos, C. (2017). I did it my way. Journal of Historical Research in Marketing, 9(3), pp. 277-301.

Hutt, M.D. (2008). Engaging corporate partners to bridge the theory-practice gap. Journal of Supply Chain Management, 44(2), pp. 68-71.

Hutt, M.D. \& Walker, B.A. (2015). Bridging the theory-practice gap in business marketing: Lessons from the field-the JBBM at 21. Journal of Business-to-Business Marketing, 25(1-2), pp. 67-72.

Lambert, D.M. (2014). Supply Chain Management: Processes, Partnerships, Performance (4th ed.). Ponte Vedra Beach, FL: Supply Chain Management Institute.

Lambert, D.M. \& Cooper, M.C. (2000). Issues in supply chain management. Industrial Marketing Management, 29(1), pp. 65-83.

Lambert, D.M. \& Enz, M.G. (2017). Issues in supply chain management: Progress and potential. Industrial Marketing Management, 62(1), pp. 1-16.

Rathmell, J.M. (1974). Marketing in the Service Sector. Cambridge, MA: Winthrop Publishers.

Tarasi, C.O., Bolton, R.N., Hutt, M.D., \& Walker, B.A. (2011). Balancing risk and return in a customer portfolio. Journal of Marketing, 75(3), pp. 1-17. 